REVISTA DE DERECHO UNED, NÚM. 10, 2012

\title{
LA CONFIGURACIÓN DE LOS DERECHOS DE ASOCIACIÓN Y DE SINDICACIÓN: UNA PROPUESTA HERMENÉUTICA
}

\author{
Miguel Tudela-Fournet \\ Universidad Autónoma de Madrid
}

Resumen: En este trabajo se propone una lectura de la evolución teórica y filosófica de la configuración de los derechos de asociación y sindicación, desde sus primeras enunciaciones hasta su consolidación constitucional, reflejando las continuidades y discontinuidades que los han ido forjando, con el objetivo de encontrar una explicación que dé cuenta de la redacción exacta de esos derechos en la Constitución Española de 1978, desde una perspectiva comparada.

Abstract: This paper proposes a reading of the theoretical and philosophical evolution of the configuration of the rights of association, from its first pronouncements to its constitutional, reflecting the continuities and discontinuities that have forged it, with the aim of explaining the reasons for the exact wording of these rights in the Spanish Constitution of 1978, from a comparative perspective.

Palabras clave: Derecho de asociación, derecho de sindicación, pensamiento comunitarista, Constitución Española.

Key words: Right of association, rights of trade unions, communintarian thought, Spanish Constitution.

Sumario: I. Introducción.-II. Metodología.-III. Consideraciones previas y breve contextualización.-IV. Los derechos de asociación y de sindicación: propuesta hermenéutica.-V. Conclusión. 


\section{INTRODUCCIÓN}

El lenguaje no sólo describe la realidad, sino que la informa, la construye. Esta ambivalencia, esta doble capacidad del lenguaje, la explica Jonathan POTTER a través de las metáforas del espejo y del taller de construcción.

En la metáfora del espejo existe un conjunto de objetos del mundo que se reflejan en una superficie lisa, aunque en este caso la superficie no es de cristal sino de lenguaje. El lenguaje refleja cómo son las cosas mediante descripciones, representaciones y relatos. Y a medida que estas descripciones, representaciones y relatos se divulgan por el mundo de los asuntos humanos, se pueden considerar fiables, factuales o literales o, por el contrario, se pueden convertir en confusiones o mentiras cuando el espejo se enturbia o se deforma.

(...) La metáfora de la construcción funciona en dos niveles cuando se aplica a las descripciones. El primero es la idea de que las descripciones y los relatos construyen el mundo, o por lo menos versiones del mundo. El segundo es la idea de que estos mismos relatos y descripciones están construidos. Aquí, «construcción» sugiere la posibilidad de montaje, fabricación, la expectativa de estructuras diferentes como punto final, y la posibilidad de emplear materiales diferentes en la fabricación ${ }^{1}$.

En esa misma línea de pensamiento, LANDOWSKI afirma que «le discours ne reflète pas le social: il le construit.» ${ }^{2}$. Por eso, decimos que, simultáneamente, la realidad construye las teorías que la explican y que esas mismas teorías construyen nuevas realidades.

Del mismo modo que los pensamientos y las teorías, políticas en nuestro caso, expuestas por un autor cualquiera tienen su repercusión en el mundo social y político que le rodea, pudiendo el investigador o el observador atento evaluar, medir y analizar la influencia que la teoría de ese autor ha ejercido sobre la práctica política, a través del estudio de esos reflejos en la realidad se puede recorrer el camino inverso, es decir, llegar a las ideas que constituyen el pensamiento de un autor a través de sus efectos sobre la realidad.

En este trabajo pretendemos recorrer ese camino inverso, desde los derechos de asociación y sindicación, hasta sus primeras formulaciones teóricas, tratando de averiguar quién o quiénes se esconden detrás de la "autoría» de esos derechos, siguiendo su configuración a lo largo del tiempo, sus primeros planteamientos, sus posteriores

\footnotetext{
1 POTTER, J., La representación de la realidad, Barcelona, Paidós, págs. 129-130.

2 LANDOWSKI, G., La société réfléchie París, Seuil, 1989, pág. 290.
} 
modificaciones, sus reformulaciones, con el objetivo de encontrar una explicación que dé cuenta de la redacción exacta de esos derechos, de sus inclusiones y de sus exclusiones, de sus alusiones y de sus omisiones, en la Constitución Española de 1978.

\section{METODOLOGÍA}

Fernand BRAUDEL consagró gran parte de su vida intelectual al estudio, desde una perspectiva histórica, del mar Mediterráneo, un personaje "complexe, encombrant, hors série. Il échappe à nos mesure et à nos catégories ${ }^{3}$. Esa complejidad, esa inconmensurabilidad del objeto de estudio sólo pudo abordarla a través del análisis minucioso y detallado de los procesos de longue durée, un análisis que le permitió explicar la forma en que ciertas costumbres sociales cristalizaron de una forma o de otra en las diferentes sociedades que habitan la cuenca mediterránea, cuáles y cómo se habían modificado ligeramente, incorporándoles nuevos elementos autóctonos, qué rasgos permanecían a pesar de todo contexto, encontrando las continuidades transfronterizas y diacrónicas. Esa forma de abordar el tema supuso no sólo su consagración como pensador, sino que además ofreció una nueva forma de entender el quehacer histórico.

Ricardo SANMARTÍN, por su parte, ha dedicado gran parte de sus estudios antropológicos a la experiencia humana del arte, sobre todo en su faceta creativa, unos estudios que, metodológicamente, ponen siempre el acento en la relación que la obra de arte, única e irrepetible, establece con su contexto.

Si nos limitáramos en el estudio del arte al cuadro mismo, a su análisis plástico e iconográfico, tomándolo como única unidad de análisis, estaríamos practicando un tipo de análisis que, condensando la historia de los símbolos, se aplica universalizando una interpretación descontextualizada. Sin duda hemos de referirnos al cuadro. Pero éste no es más que el punto de encuentro, el momento de un proceso, el cruce o el nudo de un sinfín de conexiones ${ }^{4}$.

Por analogía, desde nuestra perspectiva, en este ensayo vamos a intentar descubrir qué ideas, políticas y filosóficas, han ido configurando los derechos de asociación y de libre sindicación y de huelga tal

3 BRAUDEL, F., La Méditerranée et le monde méditerranéen à l'époque de Philippe II. 1.- La part du milieu, París, Armand Colin, 1990, pág. 11.

4 SANMARTÍN, R., Meninas, espejos e hilanderas, Madrid, Trotta, 2005, págs. 216-217. 
y como aparecen redactados en los artículos 22 y 28 de la Constitución Española de 1978, dando siempre por cierto que la filosofía informa el derecho y que la historia informa, en cierta medida, la filosofía y el pensamiento, desde la premisa de que la enunciación concreta de un derecho, cualquiera que éste sea, se puede estudiar como un punto nodal que sintetiza la interacción de distintas tradiciones de pensamiento y de las distintas posiciones intelectuales sostenidas por los diversos autores que, en mayor o menor medida, han contribuido a su definición, en una exégesis que se aproxima al método genealógico de FOUCAULT, método que «donne priorité à la recherche d'éléments hétérogènes, disparates, "divers" dont la reunión conduit de manière contingente à l'émergence de la singularité étudiée»"

Asimismo, y también por analogía del análisis de los procesos de longue durée, trataremos de descubrir qué ideas y pensamientos se han ido repitiendo y recogiendo en las obras de los distintos pensadores que han contribuido, con sus diferentes aportaciones, con sus inclusiones y exclusiones temáticas, con sus matizaciones a las ideas de otros, a la definición de estos derechos, detectando las continuidades y discontinuidades, las intermitencias, las redundancias, las citas, las referencias, los ecos que han perfilado los derechos de asociación, de sindicación y de huelga. Unas continuidades y discontinuidades, unas intermitencias, que ponen en diálogo a diversos autores y pensadores, sugiriendo que la influencia de unos sobre otros se entrelaza y se imbrica a distintos niveles, de la misma forma en que:

les marge d'un livre ne sont jamais nettes ni rigoureusement tranchées: par-delà le titre, les premières lignes et le point final, pardelà sa configuration interne et la forme qui l'autonomise, il est pris dans un système de renvois à d'autres livres, d'autres textes, d'autres phrases: noeud dans un réseau ${ }^{6}$.

\section{CONSIDERACIONES PREVIAS Y BREVE CONTEXTUALIZACIÓN}

Antes de adentrarnos en el análisis debemos ponernos de acuerdo en ciertos supuestos. El primero es que los derechos, y en especial los

5 GAUTIER, C., «À propos du "Gouvernement des conduites" chez Foucault: quelques pistes de lectura», en CHEVALLIER, J. (coord..), La gouvernabilité, París, Presses Universitaires de France, 1996, pág. 21.

6 FOUCAULT, M., L'archéologie du savoir, París, Éditions Gallimard, 1969, pág. 34. 
derechos sociales, necesitan de una larga trayectoria, podemos decir que vital e intelectual, jalonada por las aportaciones de muchos y distintos pensadores, para darles la forma que hoy conocemos. El segundo es que los derechos cuyo análisis vamos a abordar son derechos de los que hemos dado en llamar sociales.

Dicho esto, pasaremos a preguntarnos qué o quiénes se esconden entre los bastidores de estos artículos que consagran el derecho de asociación y de libre sindicación y de huelga, los artículos 22 y 28 de la Constitución Española de 1978, respectivamente, y que rezan así:

Artículo 22. 1. Se reconoce el derecho de asociación.

2. Las asociaciones que persigan fines o utilicen medios tipificados como delito son ilegales.

3. Las asociaciones constituidas al amparo de este artículo deberán inscribirse en un registro a los solo efectos de publicidad.

4. Las asociaciones sólo podrán ser disueltas o suspendidas en sus actividades en virtud de resolución judicial motivada.

5. Se prohíben las asociaciones secretas y las de carácter paramilitar.

Artículo 28. 1. Todos tienen derecho a sindicarse libremente. La Ley podrá limitar o exceptuar el derecho a las Fuerzas o Institutos armados o a los demás Cuerpos sometidos a disciplina militar y regulará las peculiaridades de su ejercicio para los funcionarios públicos. La libertad sindical comprende el derecho a fundar sindicatos y a afiliarse al de su elección, así como el derecho de los sindicatos a formar confederaciones y a fundar organizaciones sindicales internacionales o afiliarse a las mismas. Nadie podrá ser obligado a afiliarse a un sindicato.

2. Se reconoce el derecho a la huelga de los trabajadores para la defensa de sus intereses. La Ley que regule el ejercicio de este derecho establecerá las garantías precisas para asegurar el mantenimiento de los servicios esenciales de la comunidad.

La respuesta más intuitiva, más evidente, es que, detrás de estas líneas, se esconde la figura de Karl MARX. Y, en parte, eso es cierto. Al fin y al cabo «Marx desafió al liberalismo no sólo en este o aquel aspecto, sino en toda su extensión ${ }^{7}$, de donde se deduce que es lógico pensar en él.

Pero, si nos atenemos a la letra, stricto sensu, del pensamiento marxista, resulta que donde dice que «todos tienen derecho a sindi-

7 LICHTHEIM, G., Breve historia del socialismo, Madrid, Alianza Editorial, 1990, pág. 101. 
carse libremente», debería decir algo parecido a «todos los proletarios tienen el derecho legal y la obligación moral de asociarse libremente». $\mathrm{O}$, más precisamente, ateniéndonos stricto sensu a la letra del pensamiento marxista, estos derechos ni siquiera existirían, porque la sociedad comunista, la sociedad proletaria, habría disuelto el Estado burgués y no haría falta positivar ningún derecho, pues, acabada la alienación que ha condenado al hombre a la infelicidad (reseñemos aquí que los planteamientos de MARX no dejan de ser, en el fondo, una antropología eudaimonista y propositiva), no habría lugar para autoridad alguna, y los seres humanos viviríamos en comunidades en una especie de medio estado de naturaleza industrializado, sin ningún tipo de poder político opresor que restringiera nuestros márgenes de libertad.

Pero aceptemos por buena, por un momento, la enunciación de estos derechos en boca de MARX. En ella, los derechos de asociación y de sindicación coinciden. Y así vamos a abordar su estudio en este trabajo, a la maniera de MARX, desde el enfoque más puramente marxista que consideraba que "toda lucha de clases es una lucha política» y que «la organización de los proletarios como clase (...) vale decir como partido político» ${ }^{8}$. Es decir, desde una concepción puramente marxista que consideraba que asociación (política) y sindicación eran una misma expresión de unos mismos medios para conseguir unos mismos fines.

Pero, antes de iniciar un análisis más exhaustivo, hay que dejar clara una idea sobre el contexto que no debe pasar inadvertida bajo ningún concepto: Europa, en el siglo XIX, estaba viviendo el mayor terremoto social, económico y político que, hasta la fecha, jamás se había visto, a causa, principalmente, de la Revolución Industrial.

Inventos, pensamientos, nuevas ideas surgen en la Europa de entonces con una fecundidad y una velocidad jamás antes conocidas. OWEN, SAINT SIMON, WEITLING, BAUER, LEROUX, BUCHEZ, CABET, O'BRIEN,... producen la gran mayoría de los pensamientos que han configurado el mundo tal y como lo conocemos hoy en un período de tiempo inferior a los ciento cincuenta años, los que van desde la Revolución Industrial hasta la Revolución Rusa.

Europa es un hervidero de ideas y de contraideas que van y vienen de una punta a otra del continente sin tener tiempo casi de digerirlas. El tiempo y el espacio se empiezan a contraer hasta casi producir,

8 MARX, K. y ENGELS, F., El manifiesto comunista, Madrid, Editorial Ayuso, 1977, pág. 33. 
valga la hipérbole, una pequeña aldea global. Tanto es así que Rimbaud resumió con acierto el espíritu de aquellos años con su frase «Il faut être absolument modernes» ${ }^{9}$. O, mejor aún, y en la misma línea, en su poema de un solo verso "L'HUMANITÉ chaussait le vaste enfant Progrès» ${ }^{10}$.

En ese contexto, seguir la pista de las ideas en la historia reciente del pensamiento nos exige leer con espíritu crítico los artículos referentes a los derechos de asociación y de sindicación en la Constitución Española y preguntarnos qué late tras sus palabras, tras sus formulaciones jurídicas: «todos tienen derecho a sindicarse libremente», "se reconoce el derecho de asociación». En esas palabras se sintetizan ciertas concepciones de la libertad individual y colectiva, de la democracia, del mutualismo, del federalismo, de la alienación no sólo marxista, de la igualdad, de la división social entre burguesía y proletariado,... que vamos a intentar desentrañar a través del pensamiento de los autores que han ido aportando, cada uno en su medida, a la redacción de estos artículos.

Volviendo al asunto del enfoque marxista sobre los dos derechos, de asociación y de sindicación, y habiendo expuesto que se va a abordar su estudio conjuntamente, conviene explicar, aunque sea de forma somera, qué argumentación dialéctica ha llevado a formularlos por separado. Al fin y al cabo, si fueran sólo un derecho, no habría razón alguna para positivarlos en dos distintos.

A nuestro entender, fue BAKUNIN quien cuestionó con más acierto el enfoque unitario de MARX. Siguiendo su línea de argumentación, el proletariado debe construir una sociedad sin poder opresor, es decir, sin poder alguno; una sociedad de iguales cuya tradición arranca en BABEUF (1760-1797). Y, siendo el poder el objetivo de cualquier partido político, se hace evidente la necesidad argumental de separar asociación (política) y sindicación, aún a pesar de que BAKUNIN renunciara a toda lucha política.

\section{LOS DERECHOS DE ASOCIACIÓN Y DE SINDICACIÓN: PROPUESTA HERMENÉUTICA}

Nuestro punto de partida, espacio común que comparten todos los teóricos comunistas, salvo contadas excepciones, es el pauperis-

\footnotetext{
9 RIMBAUD, A., Oeuvres complètes, París, La Pléiade, 1979, pág. 116.

10 RIMBAUD, A., Poesías completas, Madrid, Editorial Cátedra, 2001, pág. 442.
} 
mo, cuyas primeras formulaciones teóricas podemos atribuir al cura MESLIER (1664-1729), pero, sobre todo, a LINGUET (1736-1794), autores tardíos del siglo XVIII a los que «no parece justificado denominar socialistas $»^{11}$ propiamente, pero que, junto a las ideas enunciadas por MABLY (1709-1785) y MORELLY (1717-?), pensadores protocomunistas que habían enunciado ya la comunidad de bienes como posible solución a la corrupción moral que conllevaba la propiedad privada, describen una situación social en la Francia de entonces, absolutamente miserable, en su acepción más próxima a la de VÍCTOR HUGO. Es más, de LINGUET, LICHTENBERGER afirma:

Es uno de los escasos escritores anteriores a 1789 de los que se puede decir, con algún fundamento, que es más un precursor de Karl MARX que un antecesor de FOURIER o de CABET ${ }^{12}$.

Ese pauperismo va a ser el punto de arranque de todos los pensamientos sociales que va a darnos el siglo XIX. Reorganizar la sociedad, repartir mejor los bienes, satisfacer las necesidades materiales de la población más empobrecida, van a ser constantes del pensamiento comunista.

Mención aparte merece, dentro del conjunto de ideas comunistas, a pesar de la poca influencia que ejerció en el resto de pensadores, Gerrard WINSTANLEY (1609-1676), cuyo pensamiento también se construye sobre el pauperismo, pero que llega más lejos que ningún otro de sus coetáneos en sus propuestas:

El comunismo de WINSTANLEY es único en la filosofía política del siglo XVII. Habla con la voz auténtica del utopismo proletario, dando expresión a los primeros balbuceos de aspiración política de las masas inarticuladas y estableciendo como meta de una sociedad justa el bienestar del hombre corriente ${ }^{13}$.

En cualquier caso, sobre ese pauperismo del que hablábamos construye Robert OWEN (1771-1858) la mayor parte de su pensamiento. A Robert OWEN le debemos sobre todo la idea del mutualismo y la de una bolsa nacional equitativa para obreros, una especie de mercado en el que se intercambiaban bonos de trabajo al estilo de la novela Walden 2, de B. F. SKINNER. Unas ideas cooperativistas que se van a constituir el primer fundamento del pensamiento socialista desde el mismo comienzo de su andadura, ya que:

11 TOUCHARD, J., Historia de las ideas politicas II, Madrid, Círculo de Lectores, 1990, pág. 56.

12 Citado en TOUCHARD, J., op. cit., pág. 59.

13 SABINE, G., Historia de la teoría politica, Madrid, Fondo de Cultura Económica, 2000, pág. 381 . 
El término «socialista» aparece por primera vez en la revista Cooperative, en el número de noviembre de 1827. El mismo año, Robert OWEN (...) publicó en New Harmony Gazette una serie de artículos bajo el título "Sistema Social» cuyo punto clave se cifraba en que «social» significaba «cooperación» ${ }^{14}$

Estas aportaciones van a tener su repercusión en el mundo de las ideas porque van a cimentar la idea del apoyo mutuo obrero, asentando las bases de una protoconciencia de clase y de los beneficios de asociarse; es decir, una forma primitiva de sindicarse que recogerá después FOURIER, criticará constructivamente PROUDHON, matizará Louis BLANC y perfeccionará después Karl MARX, sentando las bases teóricas para que Ferdinand LASALLE, a pesar de reducciones y simplificaciones de la teoría marxista, fundara la primera organización sindical del mundo en 1863, con tintes de partido político, y el primer partido político obrero en 1875, con tintes de sindicato.

Hijo ilegítimo del pensamiento de OWEN y del luddismo es el movimiento de los cartistas, considerado el primer movimiento popular obrero de la historia y fundado por disidentes del owenismo, que defienden:

que la conquista de los derechos políticos es el único medio para asegurar una nueva distribución de las riquezas, y que la democracia es el camino más corto para llegar al socialismo ${ }^{15}$.

Más volcado hacia reivindicaciones políticas que hacia la mejora de la situación material de los obreros, más volcado hacia el reconocimiento de derechos por parte del Estado que hacia la construcción de una nueva sociedad separada de la política, tal y como propugnaba Owen, a este movimiento le debemos una idea clave del pensamiento político y social actual. Entre sus filas se contaba William BENBOW (1784-1841), tabernero de oficio y padre de la idea de huelga general como mecanismo de presión para el reconocimiento de los derechos.

El pensamiento comunista inglés tuvo su respuesta legal en el primer tercio del siglo XIX. Como dice MARX en «El Capital»:

${ }^{14}$ LICHTHEIM, G., op. cit., pág. 56. TOUCHARD discrepa de esta afirmación: «El término «socialismo» aparece, casi simultáneamente, en Francia y en Inglaterra entre 1830 y 1840, pero la palabra posee en esta época un sentido bastante vago». En cualquier caso, reconoce la impronta que el pensamiento de Owen deja sobre su significado inmediatamente, cuando añade: «Así, para Pierre Leroux, el socialismo se opone al individualismo (...); para Robert Owen el socialismo es principalmente un sistema de asociaciones cooperativas» op. cit., pág. 198.

15 TOUCHARD, op. cit., pág. 204. 
No bien la clase obrera, aturdida por el estruendo de la producción, recobró el conocimiento, comenzó su resistencia, y en primer lugar en el país natal de la gran industria, en Inglaterra. Sin embargo, las concesiones por ellos arrancadas durante tres decenios fueron puramente nominales. De 1802 a 1833 el parlamento promulgó cinco leyes laborales, pero fue tan astuto que no votó un solo penique para su aplicación coercitiva, para el personal funcionarial necesario, etc. Quedaron en letra muerta ${ }^{16}$.

Siguiendo la pista del pauperismo y de la crítica de la sociedad capitalista, Saint SIMON (1760-1825), primer pensador francés interesado en la reorganización del trabajo basada en un sistema científico, positivista (tanto es así que fue su secretario Auguste COMPTE), fruto de su amor por la ciencia (casi podríamos decir que es el precursor del futurismo, de una «religión del progreso»), divide la sociedad en productores y zánganos, anunciando veladamente la lucha de clases que luego utilizará MARX y que ya había apuntado BABEUF en su Manifiesto de los iguales, redactado por Sylvain MARÉCHAL en 1796. Esto no quiere decir ni mucho menos que SAINT SIMON fuera ni demócrata ni creyera en la igualdad; bien al contrario, creía que la diferenciación de clase era necesaria y beneficiosa, y que a la cabeza de la sociedad, en la cúspide de la pirámide social, debían estar los sectores crediticios y bancarios, lo que puede parecernos un tanto extraño desde la perspectiva de hoy en día, pero que, si repasamos las actuaciones de rescate a la banca de los últimos tiempos, parece que sitúan el pensamiento de SAINT SIMON no tan lejos de nuestra contemporaneidad.

Además, a SAINT SIMON le debemos, entre otros méritos, haber formulado el problema social en términos materiales y haber sido el primero que, a pesar de no creer que las esferas de lo político y lo social ni fueran ni debieran ir juntas (como luego BAKUNIN, aunque por motivos diferentes), sí implicaba al Estado como sujeto activo y garante de esta reforma social necesaria, línea de pensamiento que tendría sus continuadores, como FOURIER, y sus detractores, como MARX.

En la línea de pensamiento de la sindicación, el siguiente autor al que debemos referirnos es a Charles FOURIER, padre intelectual de los falansterios. Excéntrico, su obra es un claro ejemplo de flexibilidad metodológica:

16 MARX, K. El capital. Libro primero. El proceso de formación del capital. México, Siglo XXI Editores, 2005, pág. 336. 
La obra de de Charles FOURIER (1772-1837), plena de extraños desarrollos (¿cómo hacer que le gusten las matemáticas a una joven a la que gusta el ajo?) y de profecías extravagantes (el agua de mar llegará a ser potable y las ballenas serán sustituidas por antiballenas que ayudarán a tirar de los barcos), ha ejercido una influencia no desdeñable ${ }^{17}$

FOURIER ideó todo un sistema de reorganización social, compartiendo inquietudes con SAINT SIMON, que, podemos decir, desarrollaba el mutualismo de OWEN. El falansterio, una especie de comunidad, de entre mil seiscientas y dos mil personas, que se dedicaba al trabajo manufacturado y al cultivo de la tierra alternativamente para poder realizarse como personas, tanto material como espiritualmente, no es ni mucho menos un sindicato, ni siquiera una asociación igualitaria, pero deja entrever la idea de lo que luego MARX, corrigiendo a HEGEL y a FEUERBACH, llamaría alienación. Para poner en marcha estos falansterios, FOURIER pensaba que tanto el Estado como la codicia capitalista le ayudarían, con lo que, en busca de inversores, prometía cuantiosos dividendos y beneficios, siempre gracias a su modelo de producción, mucho más humano, lógico y eficiente. Evidentemente, esta perspectiva productiva no es la que ha seguido configurando la idea de la sindicación, pero el falansterio, que llegó a ponerse en marcha en algunas regiones del mundo, ahondó en la idea oweniana de que la asociación obrera era mucho más rentable $\mathrm{y}$ eficiente.

Contradiciendo a sus predecesores, PROUDHON (1809-1865) recupera literalmente el espíritu igualitarista de BABEUF, aquél que reclama la «igualdad real o la muerte» ${ }^{18}$, y pone sobre aviso a los demás pensadores comunitaristas anunciando que no se puede confiar en el Estado, ya que el Estado es la encarnación administrativa de la burguesía. Para garantizar esta igualdad, PROUDHON propone el federalismo en lo político y el mutualismo en lo social, ideas que responden a su concepción de que la libertad individual se traduce, en la vida en sociedad, en solidaridad. Además, sus reflexiones sobre el mutualismo, en las que desarrolla la bolsa nacional equitativa para obreros oweniana y las traduce en el Banco del Pueblo como lugar de intercambio de bienes entre los trabajadores, aseguran, con acierto, que no existe el intercambio justo y que cualquier reparto, por equitativo que sea, va a ser siempre ventajoso para una de las partes.

17 TOUCHARD, J. op. cit., pág. 210.

18 MARÉCHAL, S., "El manifiesto de los iguales», Youkali. Revista crítica de las artes y el pensamiento, núm. 3, 2007, pág. 128. 
Esta idea de federalismo en lo político es la que va a recoger el movimiento anarquista para legitimar la igualdad de todos los miembros de la sociedad. Por último, hay que señalar que PROUDHON anunció en su «Filosofía de la miseria», publicada en 1846, que el pensamiento comunista o socialista no debía de tratar de igualar a la sociedad en negativo, es decir, en el pauperismo, que era el riesgo que entrañaba este pensamiento igualitario tal y como estaba siendo planteado hasta entonces.

Aquel libro le costó la ruptura con MARX y ENGELS, representantes del socialismo científico, pretendida única y verdadera doctrina del socialismo, quienes respondieron a PROUDHON un año más tarde con el libro «Miseria de la filosofía», condenándole al ostracismo intelectual. A la luz de los datos con que trabajamos hoy, nos puede parecer que el juicio de PROUDHON no era tan aventurado, tal y como lo atestiguan los países que orbitaban en torno a la antigua Unión de Repúblicas Socialistas Soviéticas.

Un año más tarde de la publicación de esta respuesta al libro de PROUDHON, MARX y ENGELS dieron a conocer su «Manifiesto comunista» (1847).

Pero, siguiendo con las líneas de pensamiento sindicalistas y asociativas, tenemos que reseñar a Louis BLANC (1811-1882), que recupera las inquietudes compartidas de OWEN, SAINT SIMON y FOURIER, más olvidadas tal vez por PROUDHON, sobre la organización del trabajo.

Consciente del sentimiento de ajenidad que podía producir en los trabajadores la no posesión de sus propios instrumentos de trabajo, como una rémora del pensamiento de FOURIER y como un anticipo, otra vez, de la alienación marxista, BLANC propone la creación de talleres sociales en los que los trabajadores puedan intercambiar instrumentos, herramientas y hasta productos manufacturados como contrapeso al capitalismo, creyendo, en su fuero interno, que estos lugares de intercambio alternativos al mercado lograrían suplantarlo y acabar con el sistema capitalista.

De esta forma, tras un periodo de transición en el que subsistiría de alguna manera un doble sector, libre y nacionalizado, el sistema de los talleres sociales se propagaría poco a poco y terminaría por extenderse al conjunto de la economía ${ }^{19}$.

19 TOUCHARD, op. cit., pág. 225. 
Esta idea de sustitución de un modelo por otro, formulada previamente por los teóricos de la comunidad de bienes, es la que van a arrastrar todos los pensadores comunitaristas, planteando sus modelos como modelos finales de sociedad, como modelos estáticos que hubieran llegado a la cúspide de la evolución, a la última síntesis histórica hegeliana.

En este camino de formación del corpus ideológico de los derechos que estamos estudiando, antes de dar el salto a los pensadores alemanes, debemos citar a Louis Auguste BLANQUI (1805-1881), revolucionario francés que no desatendió el aspecto intelectual de la revuelta social y que llenó de contenido combativo y reivindicativo el derecho de asociación y de sindicación. Sus ideas, que desde la perspectiva de nuestros días parecen demasiado sencillas, supusieron una vuelta de tuerca en la formación del Estado moderno, y se resumen en laicismo, instrucción y libertad. Pero, más que sus ideas generales sobre el Estado, nos interesa de BLANQUI la sistematización de la revuelta y de la movilización social, sobre todo estudiantil (siendo el pensador que crea ese nexo de unión ya inseparable entre las universidades y las demandas sociales), recogiendo la experiencia cartista y los planteamientos de William BENBOW sobre la huelga general como medio de presión.

Hecho este repaso por las ideas inglesas y francesas, por este socialismo antes de MARX, debemos repasar brevemente las ideas sociales que surgen en Prusia con un poco de retraso respecto a Francia.

Debe resultarnos curioso el que, siendo histórica la enemistad galo-germánica, fueran pensadores prusianos los que fijaran definitivamente los pilares del pensamiento socialista surgido en Inglaterra y en Francia. Esto se debe a que a principios del siglo XIX, en Prusia, empieza a disiparse el espíritu romántico, la influencia de las ideas de FICHTE y de la literatura de GOETHE, y hace que las nuevas generaciones, hijos intelectuales de HEGEL (1770-1831), miren más allá de las fronteras de la propia Prusia, aumentando el interés por lo francés, introducido por BÖRNE (1786-1837) y HEINE (1797-1856) en sus "Cartas de París» y «La escuela romántica alemana» respectivamente, en tierras germánicas y, sobre todo, por Lorenz von STEIN (1815-1902), estudiante conservador prusiano en París que escribe «El socialismo y el comunismo en la Francia contemporánea» en 1842, divulgando (y criticando) las ideas francesas.

Partiendo todos ellos de planteamientos hegelianos, la tradición de pensamiento germana ha quedado eclipsada casi en su totalidad por 
Karl MARX (1818-1883). Aún así, son señalables WEITLING (18081871) como agitador revolucionario a la manera de BLANQUI en Francia, que deriva, como OWEN, hacia un mesianismo social que entronca con otros pensadores franceses como LEROUX (1797-1871) y que va a convertirse, ya lo hemos dicho, en una de las constantes del pensamiento socialista como modelo finito de sociedad, y Ferdinand LASALLE (1825-1864), hijo intelectual, según sus propias palabras, de MARX y ENGELS (1820-1895) y con el que éstos romperían por simplificar demasiado el pensamiento marxista, por el componente nacionalista que teñía su pensamiento y que iba en contra del internacionalismo de MARX, internacionalismo que se basaba en la argumentación proudhoniana de la encarnación del Estado como Estado burgués, y en las sospechas, más tarde confirmadas en 1927 por la publicación de su correspondencia, de connivencia con BISMARCK (1815-1898). Aun así, en su haber se debe contar la creación del primer sindicato del mundo, la Asociación General de Trabajadores Alemanes, en 1863, y del Partido Obrero Socialista de Alemania, en 1875.

Paralelamente a estos debates ideológicos, en 1856, en Alemania, se empezó a legislar, aunque muy someramente, en materia laboral, prohibiendo el trabajo de niños menores de ocho años, así como el trabajo nocturno de los niños menores de diez. Un año más tarde, en Méjico, se aprobaba una Constitución liberal que empezaba a regular garantías individuales de cara al trabajo, sin llegar a ser, ni mucho menos, un derecho de sindicación como tal ${ }^{20}$, pero sí en materia de asociación, que en su artículo 9 exponía:

A nadie se le puede coartar el derecho de asociarse o de reunirse pacíficamente con cualquier objeto lícito; pero solamente los ciudadanos de la República pueden hacerlo para tomar parte en los asuntos políticos del país. Ninguna reunión armada tiene derecho de deliberar.

Esto nos interesa, sobre todo, porque inicia la vía constitucional de regulación de los derechos que estamos estudiando.

Diez años antes de esta constitucionalización, Karl MARX, como ya hemos dicho, junto con ENGELS, publicaba su «Manifiesto comunista», y fijaba, casi definitivamente, sus posiciones intelectuales y las del llamado socialismo científico.

20 Artículo 5 de la Constitución Mejicana de 1857: Nadie puede ser obligado a prestar trabajos personales, sin la justa retribución y sin su pleno consentimiento. La ley no puede autorizar ningún contrato que tenga por objeto la pérdida, o el irrevocable sacrificio de la libertad del hombre, ya sea por causa de trabajo, de educación o de voto religioso. Tampoco puede autorizar convenios en que el hombre pacte su proscripción o destierro. 
Hijo de la tradición pauperista iniciada por MESLIER y LINGUET, recoge además otras influencias filosóficas como son las de HEGEL (su dialéctica y su Espíritu de la Historia, que, junto a la voluntad general de Rousseau, le llevarían a la conclusión de que el proletariado es la clase llamada a realizar la gran revolución, encarnando el verdadero espíritu de la historia y la verdadera voluntad general de la sociedad y no sus representantes burgueses, además de su concepto de alienación, matizando los planteamientos de FEUERBACH, de la que deriva su antropología y su materialismo histórico) y formula, con más acierto que BABEUF, SAINT SIMON y BLANC, la lucha de clases. Pero, lo que nos interesa del pensamiento de Karl MARX para la formulación de los derechos de asociación y sindicación en la Constitución Española de 1978 son, principalmente, tres ideas nucleares.

La primera y más evidente es la de la dialéctica, heredada de Hegel, dado que todo sindicato y asociación parte de la idea de la defensa de unos intereses, lo que nos hace situarnos en antítesis frente a otro grupo, social, económico, político o de cualquier tipo, que se erige como nuestra tesis, dialéctica que nos podrá conducir a una ulterior síntesis. Esta dialéctica, traducida en términos marxianos en lucha de clases, encuentra su reflejo constitucional, si no en los artículos 22 y 28, sí en el artículo 7 de la Constitución Española de 1978 que versa así: «los sindicatos de trabajadores y las asociaciones empresariales contribuyen a la defensa y promoción de los intereses económicos y sociales que les son propios».

La segunda es el internacionalismo. MARX se dedica, ferozmente, a criticar los nacionalismos (lo que le llevará a romper con LASALLE, como hemos visto), utilizando los mismos argumentos que PROUDHON. Jean TOUCHARD lo explica así:

La clase que posee, dentro de los límites geográficos de una «nación», las fuerzas productivas de ese espacio, posee también esa nación; objetiva ese «bien» $\mathrm{y}$ «tiene» una patria. «Los obreros no tienen patria» ${ }^{21}$.

Este internacionalismo queda reflejado en el artículo 28 de la Constitución Española en las palabras «fundar organizaciones sindicales internacionales o afiliarse a las mismas».

Esta idea de internacionalismo nos debe conducir irremediablemente a la tercera idea nuclear, representadas por los conceptos de superestructura e infraestructura marxista como ideas que laten en el

21 TOUCHARD, J., op. cit, pág. 296. 
texto constitucional, ya que esa especie de división «vertical» del mundo macro y micro-social nos lleva de la mano, aplicando esa mecánica de pensamiento a los artículos estudiados, al derecho individual de sindicarse y de fundar sindicatos, al derecho de los sindicatos de federarse y confederarse organizativamente a nivel nacional $\mathrm{y}$ al derecho de adscribirse a federaciones y confederaciones sindicales internacionales.

Mientras tanto, mientras MARX desarrollaba todo su pensamiento (recordemos que el primer tomo de «El Capital» aparece en 1867), van sucediendo ciertos acontecimientos que marcarán los pensamientos comunista y anarquista para siempre, como la Comuna de París en 1870, un gobierno popular sobre el que, tanto MARX como BAKUNIN, reclaman la paternidad intelectual. Apenas duró tres meses, pero aún así tuvieron tiempo de publicar una reglamentación del trabajo.

En 1884 debemos reseñar otro hito histórico. En Francia se promulga la llamada Ley Waldeck-Rousseau, por la que se autorizan los sindicatos ${ }^{22}$.

Pero, habiendo visto que el derecho de asociación y de sindicación son principalmente derechos de origen social, debe llamarnos la atención que sea a «todos» a los que se autorice a sindicarse libremente en la Constitución Española de 1978. Esta matización, esta generalización del derecho de sindicación, es una aportación anarquista, tanto de BAKUNIN (1814-1876) como de KROPOTKIN (1842-1921).

La línea de pensamiento que arrastran es que la igualdad, reflejada en ese «todos», parte de BABEUF y su «Manifiesto de los iguales», pasa por OWEN y su mutualismo (aquella bolsa nacional equitativa para obreros que nos igualaría a todos) y que luego PROUDHON critica, vinculando la libertad con el federalismo en lo político y que luego BAKUNIN iusnaturalizaría en su afirmación «"la anarquía es la tendencia natural del universo, la materia es la federación de los

${ }^{22}$ Loi relative à la creation des syndicats professionnels. (21 mars 1884) Article 2: Les syndicats ou associations professionnelles, même de plus de vingt personnes exerçant la même profession, des métiers similaires, ou des professions connexes concourant à l'établissement de produits déterminés, pourront se constituer librement sans l'autorisation du Gouvernement.

Article 3: Les syndicats professionnels ont exclusivement pour objet l'étude et la défense des intérêts économiques, industriels, commerciaux et agricoles.

Article 4: Les fondateurs de tout syndicat professionnel devront déposer les statuts et les noms de ceux qui, à un titre quelconque, seront chargés de l'administration ou de la direction. 
átomos" ${ }^{23}$, de tal modo que se justificaría la federación de los individuos en la sociedad como requisito previo a la libertad y a la igualdad, tan perseguida por el pensamiento social.

Todos estos debates ideológicos han sido los que han ido configurando y fijando la forma de los derechos de sindicación y de asociación tal y como los conocemos hoy. Tanto es así que, salvo la rara avis de la Constitución Mejicana de 1857 que garantizaba el derecho de asociación, no es hasta 1917, también en Méjico, que vuelve a aparecer en una constitución algo referido a estos derechos. Parafraseando a su hermana mayor de 1857, su artículo 9 reza: «No se podrá coartar el derecho de asociarse o reunirse pacíficamente con cualquier objeto lícito».

Como vemos, todavía en 1917 no está clara la diferencia entre la asociación y la sindicación.

Catorce años más tarde nos volvemos a encontrar con esta unicidad de derechos en la Constitución Republicana Española, a pesar de que ya empieza a diferenciarlos. Su artículo 39 dice:

Los españoles podrán asociarse o sindicarse libremente para los distintos fines de la vida humana conforme a las leyes del Estado. Los sindicatos y las asociaciones están obligados a inscribirse en el registro público correspondiente con arreglo a la ley.

Si seguimos observando la trayectoria de positivación constitucional de estos derechos, debemos fijarnos en la Constitución Italiana, de 1948, que en sus artículos $39^{24}$ y $49^{25}$ garantiza la libertad de sindicación y la libertad de asociación política, respectivamente, así como la libertad de asociación general en su artículo $18^{26}$. Éste es el primer texto constitucional que distingue entre asociación y sindicación. No así la Ley de Bonn, de 1949, de la que bebe en gran parte la Constitución Española de 1978, ley que recoge en su artículo 9 tanto el derecho de asociación como el de sindicación ${ }^{27}$.

${ }^{23}$ En TOUCHARD, J., op. cit., pág. 407.

${ }^{24}$ Artículo 39: La organización sindical es libre.

25 Artículo 49: Todos los ciudadanos tendrán derecho a asociarse libremente en partidos para concurrir, mediante procedimientos democráticos, a la determinación de la política nacional.

26 Artículo 18: Los ciudadanos tienen derecho a asociarse libremente, sin autorización, para fines que no estén prohibidos por la ley penal.

27 Artículo 9. 1. Todos los alemanes tienen el derecho de crear asociaciones y sociedades.

2. Están prohibidas las asociaciones cuyos fines o cuya actividad sean contrarios a las leyes penales o que estén dirigidas contra el orden constitucional o contra la idea del entendimiento entre los pueblos. 
En lo que concierne al derecho español, debemos reseñar, como tradición jurídica, la aprobación del Fuero del Trabajo, una de las Leyes Fundamentales del régimen de FRANCO, que, en su Título Tercero, artículo $5^{28}$, habla del Sindicato, único e indivisible, basado, a su vez, en la Ley de 26 de enero de 1940 sobre Unidad Sindical, por la que se establecía que empresarios y trabajadores se integrarían en una única organización sindical, la Organización Sindical Española, más conocida como Sindicato Vertical, remarcando la importancia del sindicato como sujeto canalizador de las demandas sociales.

De este Fuero del Trabajo quedan ciertas rémoras en el pensamiento jurídico español: aquella preeminencia de los sindicatos como sujetos activos en la vida económica, política y social de nuestro ordenamiento jurídico (no extendiendo tantas garantías constitucionales a otro tipo de asociaciones civiles), que se verá reflejada en el artículo 7 de la constitución, y la ruptura que ese mismo artículo supone para con la idea de sindicato único, retomando la idea de la lucha de clases contraponiendo sindicatos y asociaciones empresariales.

Por otra parte, debemos destacar que, de acuerdo con los planteamientos anarquistas que habían separado asociación y sindicación, el régimen de FRANCO asumió jurídicamente, quién sabe si a sabiendas o no, estos postulados. Vista rápidamente la Ley de Unión Sindical, de 1940, falta por pincelar la Ley de Asociación, de 1964, una ley que se caracterizaba por una peculiar concepción del derecho de asociación, basándose en axiomas tales como que las asociaciones eran "instrumentos de los fines estatales" que necesariamente habrían "de formar parte de su peculiar estructura" y cuyos principios fundamentales se establecerían "de acuerdo con las normas inspiradoras del Movimiento nacional" ${ }^{29}$.

3. Se garantiza a toda persona y a todas las profesiones el derecho de fundar asociaciones para defender y mejorar las condiciones económicas y de trabajo. Los convenios que restrinjan o tiendan a obstaculizar este derecho serán nulos, e ilegales las medidas que se adopten con este fin. Las medidas que se adopten en virtud de los artículos 12 a, 35 apartado 2 y 3, 87a apartado 4 y 91 no podrán dirigirse contra los conflictos laborales organizados por asociaciones en el sentido de la primera frase del presente apartado con fines de salvaguardia y promoción de las condiciones económicas y de trabajo.

28 A través del Sindicato, el Estado cuidará de conocer si las condiciones económicas y de todo orden en que se realiza el trabajo son las que en justicia corresponden al trabajador.

29 PELAYO OLMEDO, D., «El derecho de asociación en la historia constitucional española, con particular referencia a las leyes de 1887 y 1964», en Historia constitucional, núm. 8, pág.113. 
Con estas maletas, con este bagaje ideológico y cultural, nuestros representantes, en las reuniones habidas en el Palacio de la Moncloa en octubre de 1977, previas a la redacción de la Constitución Española de 1978, establecieron pactos de mínimos en los que se garantizaban el derecho de reunión y el derecho de asociación política, primos hermanos de la sindicación.

La originalidad de los acuerdos de la Moncloa radica en que, a cambio de aceptar las medidas de saneamiento propuestas por el gobierno, la oposición exigió la incorporación de un paquete de reformas que pretendían el desmantelamiento de las instituciones corporativas del régimen anterior (...). En lo que a las reformas estructurales se refiere los acuerdos incluían la reforma del presupuesto estatal y del gasto público (...), una reforma del sistema financiero (...) y la reforma del marco de las relaciones laborales. Por su parte, el Programa de Actuación Jurídica y Política, adoptado en buena medida a insistencia de la izquierda, contemplaba (...) la liberalización de la legislación vigente sobre el derecho de reunión y de asociación política, así como sobre libertad de expresión ${ }^{30}$.

Así, queda inscrita en la Constitución Española aquella coletilla de que «nadie podrá ser obligado a afiliarse a un sindicato», como un espejismo de un pasado en el que la sindicación no era un derecho sino un deber.

\section{CONCLUSIÓN}

En este trabajo hemos propuesto una interpretación del camino que los derechos de sindicalización y de asociación han recorrido desde sus primeras formulaciones hasta su configuración actual.

En él, se han señalado cuáles eran las ideas nucleares y cómo se han ido perfilando a lo largo del tiempo y de los debates teoréticos que en torno a ellos se han generado, tratando de señalar cómo y cuándo fueron informándose.

La interpretación propuesta da cuenta plausible de cuál ha sido ese recorrido hasta su redacción en la Constitución Española de 1978.

En conclusión, todas las ideas que se esconden en los bastidores de estos artículos vienen de una compleja tradición de pensamiento, producida por un sinfín de intelectuales, que arranca en el siglo

30 POWELL, C., España en democracia. 1975-2000, Barcelona, Plaza y Janés, 2001, págs. 206-207. 
XVIII y que a día de hoy han sido fijadas, en nuestro modelo constitucional, como artículos de máxima garantía.

\section{BIBLIOGRAFÍA}

BRAUDEL, F. (1990). La Méditerranée et le monde méditerranéen à l'époque de Philippe II. 1.- La part du milieu. París: Armand Colin.

FOUCAULT, M. (1969). L'archéologie du savoir. París: Éditions Gallimard.

GAUTIER, C. (1996). "À propos du "Gouvernement des conduites" chez Foucault: quelques pistes de lectures». En J. CHEVALIER (coord.), La gouvernabilité. París: PUF.

LANDOWSKI, E. (1989). La société réfléchie. Paris: Seuil.

LICHTHEIM, G. (1990). Breve historia del socialismo. Madrid: Alianza.

MARÉCHAL, S. (2007). El manifiesto de los iguales. Youkali. Revista crítica de las artes y el pensamiento, núm. 3. 127-130. Consultable en www.youkali.net

MARX, K. (2005). El capital. Libro primero. El proceso de formación del capital. México: Siglo XXI Editores.

MARX, K. y ENGELS, F. (1977). El manifiesto comunista. Madrid: Ayuso.

PELAYO OLMEDO, D. (2007). El derecho de asociación en la historia constitucional española, con particular referencia a las leyes de 1887 y 1964. Historia constitucional, núm. 8. 95-122. Consultable en www.historiaconstitucional.com.

POWELL, C. (2001). España en democracia, 1975-2000. Barcelona: Plaza Janés.

RIMBAUD, A. (1979). Oeuvres complètes. Paris: La Pléiade.

- (2001). Poesías completas. Madrid: Cátedra.

SABINE, G. (2000). Historia de la teoría política. Madrid; Fondo de Cultura Económica.

SANMARTÍN, R. (2005). Meninas, espejos e hilanderas. Madrid: Trotta.

TOUCHARD, J. (1990). Historia de las ideas politicas II. Madrid: Círculo de lectores. 